\title{
Synergistic antitumor effect of suberoylanilide hydroxamic acid and cisplatin in osteosarcoma cells
}

\author{
MENGYI HOU ${ }^{1}$, ZHENGLAN HUANG ${ }^{1}$, SICHENG CHEN ${ }^{2}$, HAO WANG $^{1}$, \\ TIANYU FENG ${ }^{1}$, SHUJUAN YAN ${ }^{1}$, YUXI $\mathrm{SU}^{3}$ and GUOWEI ZUO ${ }^{1}$
}

\author{
${ }^{1}$ Key Laboratory of Diagnostic Medicine Designated by The Chinese Ministry of Education, Department of Laboratory \\ Medicine, Chongqing Medical University, Chongqing 400016; ${ }^{2}$ Department of Clinical Medicine, Xinxiang \\ Medical University, Xinxiang, Henan 453003; ${ }^{3}$ Key Laboratory of Child Development and Disorders of \\ Ministry of Education, Department II of Orthopedics, The Children's Hospital of \\ Chongqing Medical University, Chongqing 400014, P.R. China
}

Received November 27, 2016; Accepted October 20, 2017

DOI: $10.3892 / \mathrm{ol} .2018 .9224$

\begin{abstract}
Cisplatin, as a first-line chemotherapy drug, has been widely applied for therapy of osteosarcoma. However, its application is limited by drug resistance and serious side effects, including nephrotoxicity and ototoxicity. Suberoylanilide hydroxamic acid (SAHA) is a newly developed histone deacetylase (HDAC) inhibitor, which is the first Food and Drug Administration-approved HDAC inhibitor for the treatment of cutaneous manifestations of T-cell lymphoma. However, SAHA as a monotherapy was revealed to be limited, particularly in solid tumors. In the present study, 143B osteosarcoma cells were treated with multiple concentrations of SAHA or cisplatin, either alone or combined. The morphological characteristics of the treated cells were observed using an inverted microscope. The cytotoxicity effects of the combination of SAHA and cisplatin on 143B cells were analyzed by MTT assay, colony formation assay, wound healing cell migration assay, cell apoptosis assay and cell cycle analysis. Western blot analysis was performed to detect the protein expression levels of B cell lymphoma-2 (Bcl-2)-associated X protein (Bax), Bcl-2, cleaved-caspase-3, cleaved-caspase- 8 and cleaved-poly (ADP-ribose) polymerase (PARP). The experimental data indicated that the inhibition of cell proliferation in the combination group was significantly increased compared with that in single drug groups. Expression levels of pro-apoptotic protein were upregulated, whereas anti-apoptotic Bcl-2 was downregulated significantly in 143B cells following SAHA/cisplatin treatment. Taken together, the results revealed that the combination
\end{abstract}

Correspondence to: Dr Guowei Zuo, Key Laboratory of Diagnostic Medicine Designated by the Chinese Ministry of Education, Department of Laboratory Medicine, Chongqing Medical University, 1 Yixueyuan Road, Yuzhong, Chongqing 400016, P.R. China E-mail:gwzuo@qq.com

Key words: suberoylanilide hydroxamic acid, cisplatin, osteosarcoma, drug combination, synergistic effect of SAHA and cisplatin inhibited the proliferation of 143B cells and induced their apoptosis synergistically, and this effectiveness may be mediated by caspase activation.

\section{Introduction}

Osteosarcoma is the most common type of primary malignancy of bone in children, and young adults (under the age of 20) $(1,2)$. Current treatment protocols include neoadjuvant chemotherapy, surgical resection and postoperative chemotherapy. Surgical treatment has been commonly used to treat osteosarcoma patients; however, surgical procedures sacrifice a larger segment of bone and require complicated reconstruction. At present, except for surgical resection, chemotherapy is used as a standard treatment protocol for osteosarcoma, including doxorubicin, cisplatin and high-dose methotrexate with leucovorin rescue $(3,4)$.

Cisplatin, a cell cycle non-specific drug, has been widely used for clinical treatment and possesses a broad anticancer spectrum (5). Cisplatin-induced DNA damage into cytotoxicity may destroy the structure of the cell membrane, induce cell cycle arrest and/or apoptosis in cancer cells $(6,7)$. The powerful function, synergistic effect with multiple chemotherapeutic agents and lack of cross resistance, make cisplatin one of the most commonly used drugs in combination chemotherapy. However, standard chemotherapy with cisplatin is limited due to serious side effects in patients and the occurrence of cisplatin resistance (8). Decreasing cisplatin-mediated toxicity or overcoming drug resistance with the concomitant use of other drugs, is of great significance.

Previously, epigenetic alterations have been confirmed to contribute toward cancer initiation and progression in solid tumors $(9,10)$. Histone acetylation and deacetylation are epigenetic phenomena that serve critical functions in the modulation of chromatin topology and the regulation of gene expression (11). Abnormal expression or mutation of genes encoding histone acetyltransferase or histone deacetylase (HDAC) enzymes have been identified by tumorigenesis (12). Therefore, compounds that target HDACs have generated great interest as potential anticancer drugs. HDAC inhibitors 
sensitize cells to chemotherapy and radiation therapy by inducing the acetylation of lysine residues of nuclear histones and 'opening up' the chromatin (13). Conversely, the open chromatin structures may allow transcription of tumor suppressors and pro-apoptotic genes (14). The open chromatin structures provide additional target sites for DNA-damaging anticancer drugs, including cisplatin (15). Compared with conventional chemo-agents, HDAC has revealed strong antitumor activity against numerous cancer cell types in vitro and in vivo, with decreased toxicity to normal cells (15-17).

Suberoylanilide hydroxamic acid (SAHA), the most promising HDAC inhibitor (HDACI), was approved by the US Food and Drug Administration for the treatment of patients with cutaneous T-cell lymphoma in 2006 (18). SAHA is safe and non-toxic in vivo and has significant antitumor effects against multiple types of tumor cell $(19,20)$. Due to the specific and complementary mode of action, HDACIs have been reported to show additive or synergistic antitumor effects combined with platinum-based chemotherapeutic drugs, including cisplatin in numerous cancer cell lines in vitro and in vivo (21).

Therefore, the main aim of the present study was to evaluate the antitumor effects of SAHA combined with cisplatin on human osteosarcoma 143B cells. The antitumor effects of this combination on cell viability, cell apoptosis regulation and modulation of cell cycle were investigated. The present study revealed that the combination of SAHA and cisplatin may provide a novel strategy for treating osteosarcoma.

\section{Materials and methods}

Reagents and antibodies. SAHA and cisplatin were purchased from Sigma-Aldrich (Merck KGaA, Darmstadt, Germany). SAHA was dissolved in dimethyl sulfoxide (DMSO; Beijing Solarbio Science \& Technology Co., Ltd., Beijing, China) and cisplatin was dissolved in double-distilled water. These drugs were stored at $-20^{\circ} \mathrm{C}$ until use.

MTT was obtained from Beijing Solarbio Science \& Technology Co., Ltd. Cell lysis buffer (cat. no. P0013) and an SDS-PAGE kit (cat. no. P0012A) were purchased from the Beyotime Institute of Biotechnology (Haimen, China). Anti-B cell lymphoma-2 (Bcl-2) (cat. no. YT0469), rabbit anti-Bcl-2-associated $\mathrm{X}$ protein (Bax; cat. no. YT0459), anti-cleaved-caspase-3 (cat. no. YC0004), anti-cleaved-caspase-8 (cat. no. YC0011) and anti-cleaved-poly (ADP-ribose) polymerase (PARP) (cat. no. YC0101) were purchased from Immunoway (Newark, DE, USA). Mouse anti- $\beta$-actin monoclonal antibody (cat. no. TA-09) and secondary antibodies, including horseradish peroxidase-conjugated goat anti-mouse immunoglobulin (Ig)G antibody (cat. no. ZB5305) and anti-rabbit IgG antibodies (cat. no. ZB5301) were purchased from Beijing Zhongshan Golden Bridge Biotechnology., Co., Ltd. (Beijing, China). BeyoECL was purchased from EMD Millipore (Billerica, MA, USA).

Cell line and cell culture. The human 143B osteosarcoma cell line was purchased from the American Type Culture Collection (Manassas, VA, USA). The cells were maintained in a humidified atmosphere containing $5 \% \mathrm{CO}_{2}$ at $37^{\circ} \mathrm{C}$ in Dulbecco's modified Eagle's medium (Hyclone, Logan, UT, USA) supplemented with $10 \%$ fetal bovine serum (FBS; Gibco; Thermo
Fisher Scientific, Inc., Waltham, MA, USA) and $100 \mathrm{U} / \mathrm{ml}$ streptomycin/penicillin.

Cell viability assay. MTT assay was performed to analyze cell viability. Cells were plated at a density of 2-8 $\times 10^{3}$ cells/well in a 96-well plate 1 day prior to treatment at $37^{\circ} \mathrm{C}$. The cells were then treated with either SAHA $(2,4,8$, and $16 \mu \mathrm{mol} / \mathrm{l})$ or cisplatin $(50,100,200$ and $400 \mathrm{ng} / \mathrm{ml})$ alone or with a combination of SAHA $(2,4$ and $8 \mu \mathrm{mol} / \mathrm{l})$ and cisplatin $\left(100\right.$ and $400 \mathrm{ng} / \mathrm{ml}$ ) at $37^{\circ} \mathrm{C}$ for $72 \mathrm{~h}$. At the indicated time-points (24, 48 and $72 \mathrm{~h}), 10 \mu \mathrm{l}$ MTT solution $(5 \mathrm{mg} / \mathrm{ml})$ was added to each well and the plate was incubated for another $4 \mathrm{~h}$ at $37^{\circ} \mathrm{C}$. MTT reagent was then removed and formazan was dissolved in DMSO for 10 min at room temperature. Cell viability was evaluated by determining the absorbance of each well at $490 \mathrm{~nm}$ using an enzyme immunoassay analyzer (Bio-Rad Laboratories, Inc., Hercules, CA, USA). The experiment was repeated three times.

Morphological alterations of the cells. Following treatment with either SAHA ( $4 \mu \mathrm{mol} / \mathrm{l})$ or cisplatin $(100 \mathrm{ng} / \mathrm{ml})$ alone or with a combination of SAHA and cisplatin $(4 \mu \mathrm{mol} / 1 \mathrm{SAHA}+$ $100 \mathrm{ng} / \mathrm{ml}$ cisplatin) for $48 \mathrm{~h}$ at $37^{\circ} \mathrm{C}$, the morphological characteristics of the treated cells were observed. Images were captured using an inverted phase contrast microscope at a magnification of x100 (Nikon Corporation, Tokyo, Japan).

Colony-formation assay. The human 143B osteosarcoma cells were plated at a density of 1,000 cells/well onto a 6 -well culture plate for 1 day prior to treatment at $37^{\circ} \mathrm{C}$ and were then cultured in medium containing either SAHA $(4 \mu \mathrm{mol} / \mathrm{l})$ or cisplatin $(100 \mathrm{ng} / \mathrm{ml})$ alone or a combination of SAHA and cisplatin $\left(4 \mu \mathrm{mol} / 1 \mathrm{SAHA}+100 \mathrm{ng} / \mathrm{ml}\right.$ cisplatin) at $37^{\circ} \mathrm{C}$ for $48 \mathrm{~h}$. The $143 \mathrm{~B}$ cells were given fresh medium after incubation for $48 \mathrm{~h}$ and then cultured for 2 weeks at $37^{\circ} \mathrm{C}$. The cells were fixed with $4 \%$ paraformaldehyde at $37^{\circ} \mathrm{C}$ for $15 \mathrm{~min}$ prior to being stained with $0.1 \%$ crystal violet at $37^{\circ} \mathrm{C}$ for $15 \mathrm{~min}$ and images were captured using EPSON SCAN and five horizons were randomly selected to count the cell numbers. The colony-formation rate was calculated using the formula: (Colony number/seeded cell number) x $100 \%$. The experiment was repeated three times.

Wound-healing cell migration assay. 143B cells were seeded in a 6 -well plate at a density of $4 \times 10^{5}$ cells/well and cultured until $100 \%$ confluence at $37^{\circ} \mathrm{C}$. The wound was made by scraping a conventional pipette tip to make a straight scratch across the monolayer. The cells were treated with single drugs (SAHA: $4 \mu \mathrm{mol} / \mathrm{l}$; cisplatin: $100 \mathrm{ng} / \mathrm{ml}$ ) or in combination $\left(4 \mu \mathrm{mol} / 1 \mathrm{SAHA}+100 \mathrm{ng} / \mathrm{ml}\right.$ cisplatin) at $37^{\circ} \mathrm{C}$ for $48 \mathrm{~h}$ after being washed twice with PBS and the addition of medium supplemented with $2 \%$ FBS. Images were captured using an inverted phase contrast microscope at a magnification of x100 (Nikon Corporation). The experiment was repeated three times.

Flow cytometry analysis. Cell cycle analysis and the Annexin-V assay were assessed by flow cytometry. 143B cells were seeded in a 6 -well plate at a density of $3 \times 10^{5}$ cells/well, allowed to attach overnight at $37^{\circ} \mathrm{C}$, and then treated with 
A

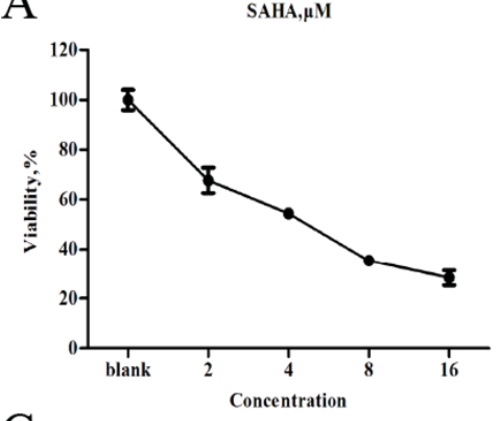

C

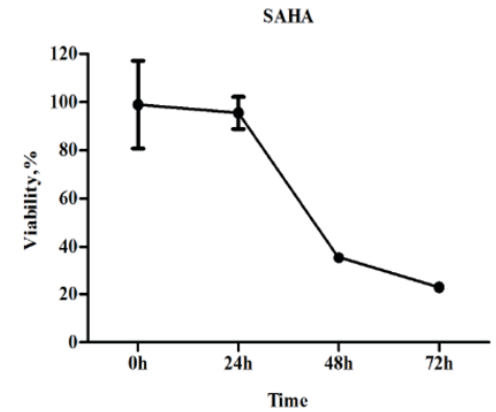

B

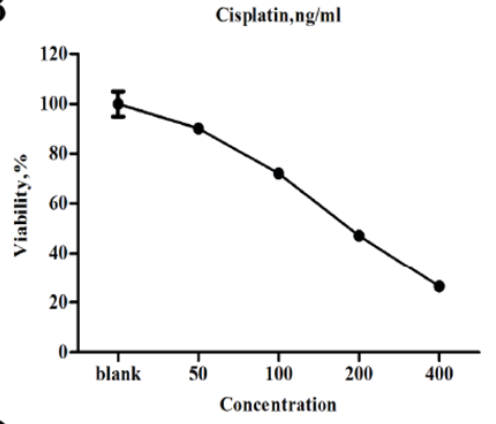

$\mathrm{D}$

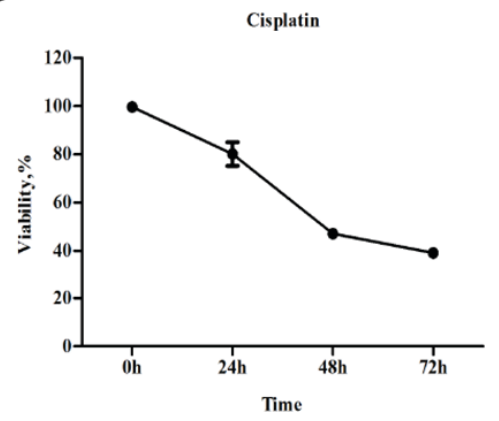

Figure 1. Effect of SAHA or cisplatin monotherapy on cell viability of 143B osteosarcoma cells. (A) Exposure to SAHA resulted in significant proliferation inhibition and cytotoxicity in 143B cells in a concentration-dependent manner. (B) Exposure to cisplatin resulted in significant proliferation inhibition and cytotoxicity in 143B cells in a concentration-dependent manner. (C) Exposure to SAHA resulted in significant proliferation inhibition and cytotoxicity in 143B cells in a time-dependent manner. (D) Exposure to cisplatin resulted in significant proliferation inhibition and cytotoxicity in 143B cells in a time-dependent manner. SAHA, suberoylanilide hydroxamic acid.

single drugs (SAHA: $4 \mu \mathrm{mol} / \mathrm{l}$; cisplatin: $100 \mathrm{ng} / \mathrm{ml})$ or in combination ( $4 \mu \mathrm{mol} / 1 \mathrm{SAHA}+100 \mathrm{ng} / \mathrm{ml}$ cisplatin) at $37^{\circ} \mathrm{C}$ for $48 \mathrm{~h}$ prior to being washed twice with PBS, harvested by trypsinization $\left(0.25 \%\right.$ trypsin for $1 \mathrm{~min}$ at $\left.37^{\circ} \mathrm{C}\right)$ and centrifuged $(500 \mathrm{x} \mathrm{g}$ for $5 \mathrm{~min}$ at room temperature). For cell cycle analysis, the harvested cells were re-suspended in pre-cold $70 \%$ ethanol for at least $4 \mathrm{~h}$ at $4^{\circ} \mathrm{C}$. The cells were dissolved in $10 \mu \mathrm{g} / \mathrm{ml} \mathrm{RNase} \mathrm{A} \mathrm{(Sigma-Aldrich;} \mathrm{Merck} \mathrm{KGaA)} \mathrm{at} 37^{\circ} \mathrm{C}$ for $20 \mathrm{~min}$. Subsequently, the cells were treated with $20 \mu \mathrm{g} / \mathrm{ml}$ propidium iodide (Sigma-Aldrich; Merck KGaA) and the DNA contents of the cells (10,000 cells/group) were evaluated using a FACSVantage SE flow cytometer (BD Biosciences, San Jose, CA, USA). For the Annexin-V assay, the harvested cells were added to $5 \mu \mathrm{l}$ FITC-Annexin V (BD Biosciences) and $10 \mu \mathrm{l}$ propidium iodide (BD Biosciences) and incubated for $15 \mathrm{~min}$ at room temperature in the dark. Binding buffer $(400 \mu 1)$ was added to terminate the reaction, then analyzed using flow cytometry (BD FACSCanto II; BD Biosciences). Data were analyzed using the BD FACSDiva ${ }^{\mathrm{TM}}$ software version 8.0 (BD Biosciences). The experiment was repeated three times.

Western blotting analysis. Cells with multiple treatments (SAHA: $4 \mu \mathrm{mol} / 1$; cisplatin: $100 \mathrm{ng} / \mathrm{ml}$; SAHA/cisplatin: $4 \mu \mathrm{mol} / 1$ and $100 \mathrm{ng} / \mathrm{ml}$ ) were washed with ice-cold PBS twice and then lysed with RIPA buffer (50 mM Tris-HCl, $150 \mathrm{mM}$ $\mathrm{NaCl}, 1 \mathrm{mM}$ EDTA, $0.1 \%$ sodium dodecyl sulfate, $0.5 \%$ deoxycholic acid, $0.02 \%$ sodium azide, $1 \% \mathrm{NP}-40,2.0 \mu \mathrm{g} / \mathrm{ml}$ aprotinin and $1 \mathrm{mM}$ PMSF) on ice, then centrifuged at 13,000 $\mathrm{x} \mathrm{g}$ for $25 \mathrm{~min}$ at $4^{\circ} \mathrm{C}$ and supernatants were collected. The protein concentration was quantified by bicinchoninic acid assay.
Protein was boiled for $10 \mathrm{~min}$ at $100^{\circ} \mathrm{C}$ in $5 \mathrm{X}$ loading buffer (Beyotime Institute of Biotechnology) and then $200 \mu \mathrm{g}$ protein per lane was separated using SDS-PAGE (10\% gel) and transferred to polyvinylidene difluoride membranes. Membranes were blocked with $5 \%$ bovine serum albumin (Beijing Solarbio Science \& Technology Co., Ltd) in Tris-buffered saline (Beyotime Institute of Biotechnology) containing Tween-20 (TBST; Sangon Biotech Co., Ltd., Shanghai, China) for $2 \mathrm{~h}$ at $37^{\circ} \mathrm{C}$ and then incubated with the primary antibodies (Bax, anti-B cell lymphoma-2, anti-cleaved-caspase-3, anti-cleaved-caspase- 8 and anti-cleaved-poly (ADP-ribose) polymerase and mouse anti- $\beta$-actin monoclonal antibody) overnight at $4{ }^{\circ} \mathrm{C}$. All primary antibodies were diluted at 1:1,000. Following washing the membranes twice with TBST buffer, membranes were incubated with the horseradish peroxidase-conjugated secondary antibodies (goat anti-mouse IgG antibody and anti-rabbit $\mathrm{IgG}$ antibodies) at $37^{\circ} \mathrm{C}$ for $1 \mathrm{~h}$. All secondary antibodies were diluted at 1:5,000. Following washing twice with TBST buffer, the protein levels were quantified using a BeyoECL kit. The mouse anti- $\beta$-actin monoclonal antibody (dilution, 1:1,000) was used as a loading control. The intensity of protein bands was quantified by densitometric analysis using Quantity One 4.6.2 program (Bio-Rad Laboratories, Inc., Hercules, CA, USA). The experiment was repeated three times.

Statistical analysis. Drug combination effects were evaluated by the Chou and Talalay method using CalcuSyn software 1.0 (Premier Biosoft International, Palo Alto, CA, USA). The experimental data were presented as the mean \pm standard deviation from at least three independent experiments. GraphPad 


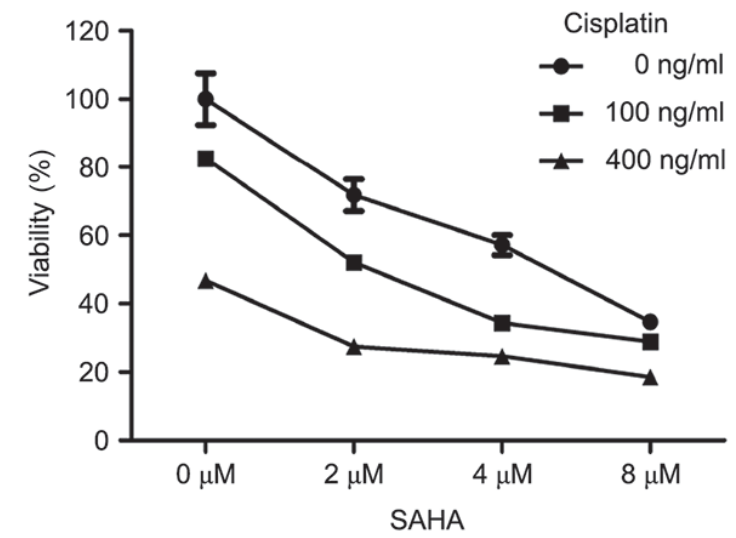

Figure 2. Combination effect of SAHA and cisplatin on the cell viability of osteosarcoma cells. Combination of SAHA and cisplatin inhibited the cell viability of 143B cells more significantly compared with the control and the individual groups $\left({ }^{*} \mathrm{P}<0.05\right)$. SAHA, suberoylanilide hydroxamic acid.

Prism Software 5.0 (GraphPad Software, Inc., La Jolla, CA, USA) was used to examine the statistical significance by SNK-q test or one-way analysis of variance followed by Student-Newman-Keuls post hoc test. $\mathrm{P}<0.05$ was considered to indicate a statistically significant difference.

\section{Results}

SAHA or cisplatin alone inhibits cell viability of osteosarcoma cells. The in vitro cell proliferation and functions of cisplatin and SAHA in 143B cells were examined by MTT assay. The results demonstrated that SAHA or cisplatin exerted a toxic effect on 143B cells at $48 \mathrm{~h}$ and revealed concentration-dependent (Fig. 1A and B) and time-dependent characteristics (Fig. 1C and D). The cell viability of 143B cells treated with SAHA or cisplatin was significantly inhibited at $48 \mathrm{~h}(\mathrm{P}<0.05)$ and was more so at $72 \mathrm{~h}(\mathrm{P}<0.01)$. Therefore, the present study selected $48 \mathrm{~h}$ as the time-point for the subsequent experiments.

SAHA/cisplatin combination has a synergistic effect on osteosarcoma cells. To determine whether SAHA is able to enhance the anti-proliferative effect of osteosarcoma cells by cisplatin, 143B cells were treated with various concentrations of SAHA (2, 4 and $8 \mu \mathrm{mol} / \mathrm{l})$ and cisplatin (100 and $400 \mathrm{ng} / \mathrm{ml}$ ) in combination. The results demonstrated that the combination of SAHA and cisplatin inhibited the proliferation of 143B cells robustly (Fig. 2). The morphological alterations due to combination treatment were also observed by microscopic examination (Fig. 3A). The effect of the combination of SAHA and cisplatin on cell proliferation was evaluated by combination indices and revealed to be synergistic (combination indices $<1$; Table I). Furthermore, the present study demonstrated a significant decrease in colony formation in the drug combination group compared with the control and the individual groups $(\mathrm{P}<0.05$ for both; Fig. 3B).

SAHA/cisplatin combination inhibited cell migration of osteosarcoma $143 \mathrm{~B}$ cells in vitro. Cell migration serves an important function in tumor metastasis (22). The wound-healing cell migration assay was performed to confirm
Table I. Combination indices for the combination of SAHA and cisplatin in 143B cells.

\begin{tabular}{lcc} 
CI & \multicolumn{2}{c}{ Cisplatin, $\mathrm{ng} / \mathrm{ml}$} \\
\hline SAHA, $\mu \mathrm{M}$ & 100 & 400 \\
\hline 2 & 0.479 & 0.726 \\
4 & 0.656 & 0.753 \\
8 & 0.712 & 0.814 \\
\hline
\end{tabular}

CI, combination indices; SAHA, suberoylanilide hydroxamic acid.

the effect of the combination treatment on cell migration. Following treatment with single drugs or in combination for $48 \mathrm{~h}$, the combination exhibited significantly decreased cell migration into the wounded area compared with that in the control group and the two individual treatment groups $(\mathrm{P}<0.05$ and $\mathrm{P}<0.05$; Fig. 3C).

SAHA/cisplatin combination stimulates apoptosis of osteosarcoma cells in vitro. To determine apoptotic cell death in osteosarcoma cells following the combination treatment, flow cytometry was performed. As presented in Fig. 4A, the early apoptotic rate of SAHA or the cisplatin group was increased compared with that of the control group $(\mathrm{P}<0.05)$ and the early apoptotic rate in the combination group was significantly increased compared with that in the control group and the two individual groups $(\mathrm{P}<0.05$ and $\mathrm{P}<0.05)$.

SAHA/cisplatin combination affected the cell cycle distribution. Cell cycle arrest serves a critical function in cell proliferation (23). To investigate the mechanisms underlying the synergistic anti-proliferative effect of SAHA and cisplatin, flow cytometry was performed to detect the changes of the cell cycle. As presented in Fig. 4B, for 143B cells treated with SAHA, cells in $\mathrm{G}_{2} / \mathrm{M}$ cell cycle phase increased from 23.58 to $68.34 \%$ and cells in $\mathrm{S}$ phase decreased from 33.43 to $5.16 \%$. Treatment of cisplatin increased cells in the $\mathrm{S}$ phase from 33.43 to $52.85 \%$ and decreased cells in the $\mathrm{G}_{2} / \mathrm{M}$ phase from 23.58 to $2.84 \%$. The results revealed that SAHA arrested the cell cycle at the $G_{2} / M$ phase $(P<0.05)$, whereas cisplatin arrested the cell cycle at the $\mathrm{S}$ phase $(\mathrm{P}<0.05)$. The combination of SAHA and cisplatin decreased the cells in $\mathrm{G}_{2} / \mathrm{M}$ phase from 23.58 to $19.22 \%$, whereas $46.68 \%$ of total cells were confined in the $\mathrm{G}_{0} / \mathrm{G}_{1}$ phase. No significant changes were noted in the $\mathrm{S}$ phase of $143 \mathrm{~B}$ cells in the combination group.

SAHA/cisplatin combination altered apoptosis-associated protein expression levels in osteosarcoma $143 B$ cells. To investigate the mechanism of apoptosis induced by SAHA and cisplatin in osteosarcoma cells, the present study analyzed the protein expression levels of Bax, Bcl-2, cleaved-caspase-3, cleaved-caspase- 8 and cleaved-PARP in 143B cells following exposure of the cells to SAHA, cisplatin and a combination of SAHA and cisplatin for $48 \mathrm{~h}$. As presented in Fig. 5A, the expression levels of pro-apoptotic protein (Bax) in the 
A

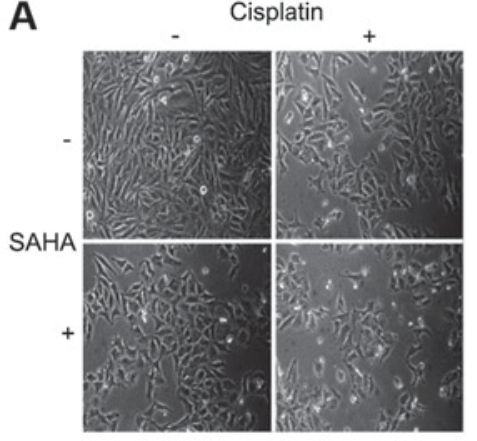

B

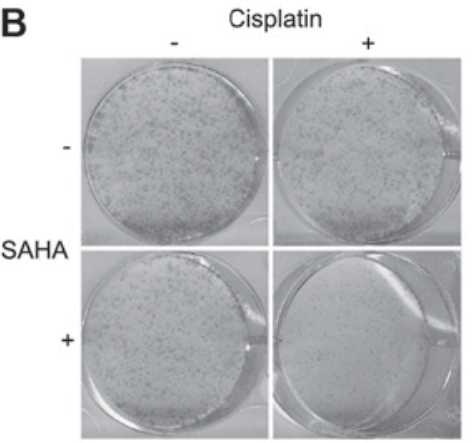

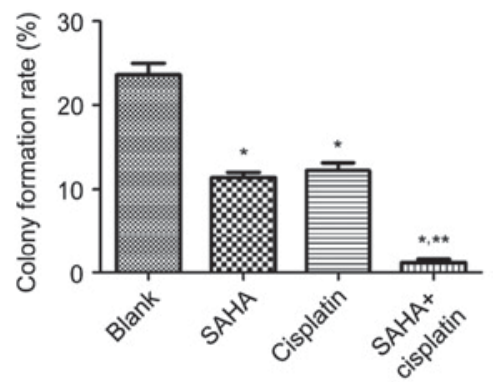

C

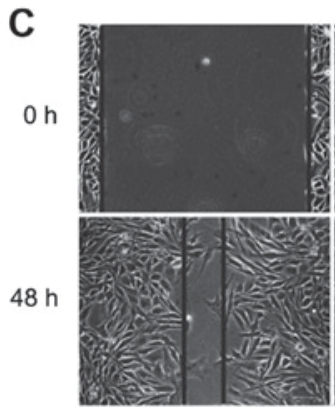

SAHA

Cisplatin

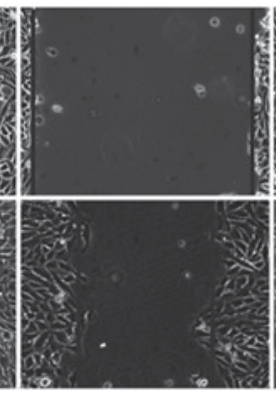

$+$ $-$

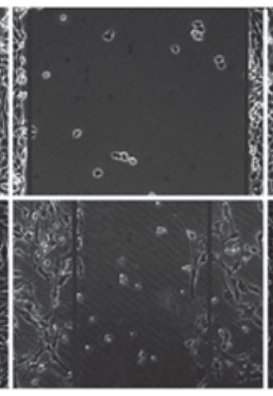

$+$

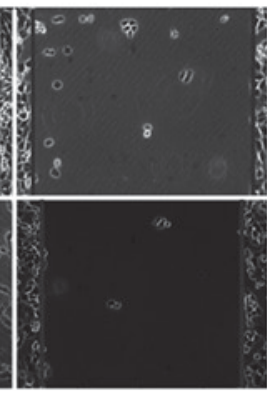

$+$

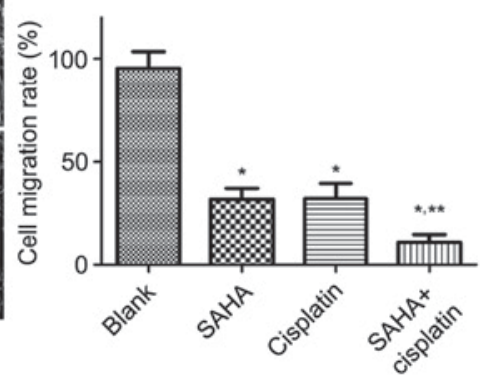

Figure 3. Morphological changes of osteosarcoma cells following exposure to SAHA, cisplatin or SAHA+cisplatin. (A) Necrosis of 143B cells was marked in the SAHA/cisplatin group (magnification, x100). (B) The number of colonies decreased significantly in the SAHA/cisplatin group in 143B cells compared with the control and the individual groups (magnification, $x 100 ;{ }^{*} \mathrm{P}<0.05$ ). (C) The combination of SAHA and cisplatin impaired migration in $143 \mathrm{~B}$ cells significantly compared with the control and the individual groups. ${ }^{*} \mathrm{P}<0.05$ vs. control; ${ }^{* *} \mathrm{P}<0.05$ vs. monotherapy. SAHA, suberoylanilide hydroxamic acid.

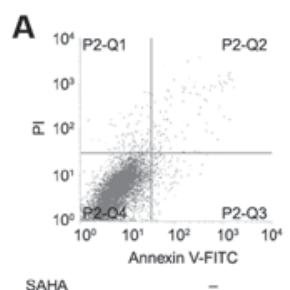

SAHA

B

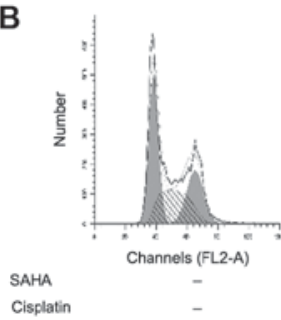

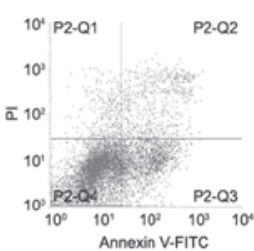

$+$

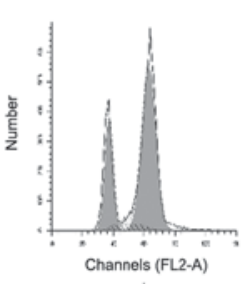

$+$

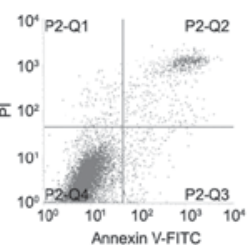

$+$

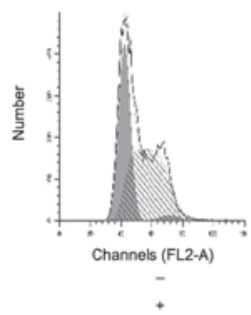

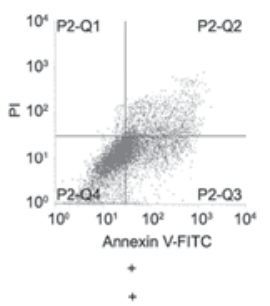
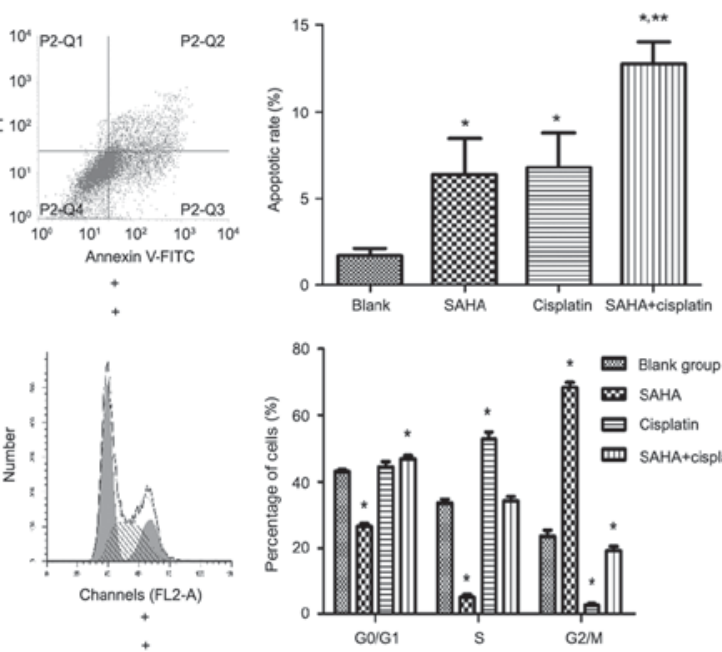

Figure 4. Flow cytometry analysis of osteosarcoma cells following exposure to SAHA, cisplatin or SAHA+cisplatin. (A) The percentage of apoptotic cells in the combination group was significantly increased compared with the control and the monotherapy groups. (B) The cell cycle distribution was altered in the combination group compared with the control and the monotherapy groups. ${ }^{*} \mathrm{P}<0.05$ vs. control; ${ }^{* *} \mathrm{P}<0.05$ vs. single treatment. FITC, fluorescein isothiocyanate; SAHA, suberoylanilide hydroxamic acid; PI, propidium iodide.

combination group were increased compared with those in the control and the two individual groups $(\mathrm{P}<0.05)$, but the expression levels of anti-apoptotic protein ( $\mathrm{Bcl}-2)$ in the combination group were decreased compared with those in the control and the two individual groups $(\mathrm{P}<0.05)$. Meanwhile, the expression levels of cleaved-caspase-3, cleaved-caspase-8, cleaved-PARP in the combination group were significantly increased compared with those in the control and the two individual groups $(\mathrm{P}<0.05$; Fig. 5B).

\section{Discussion}

Osteosarcoma is a pleomorphic malignant bone tumor most common in children and young adults $(1,2)$. Osteosarcoma usually localizes at the metaphysis of long bones and most commonly occurs in the distal femur (30\%), proximal tibia $(15 \%)$ or proximal humerus $(15 \%)$ (24). Therefore, osteosarcoma has a propensity to metastasize and recur because these regions have rich blood supplies and hematogenous metastasis 
A
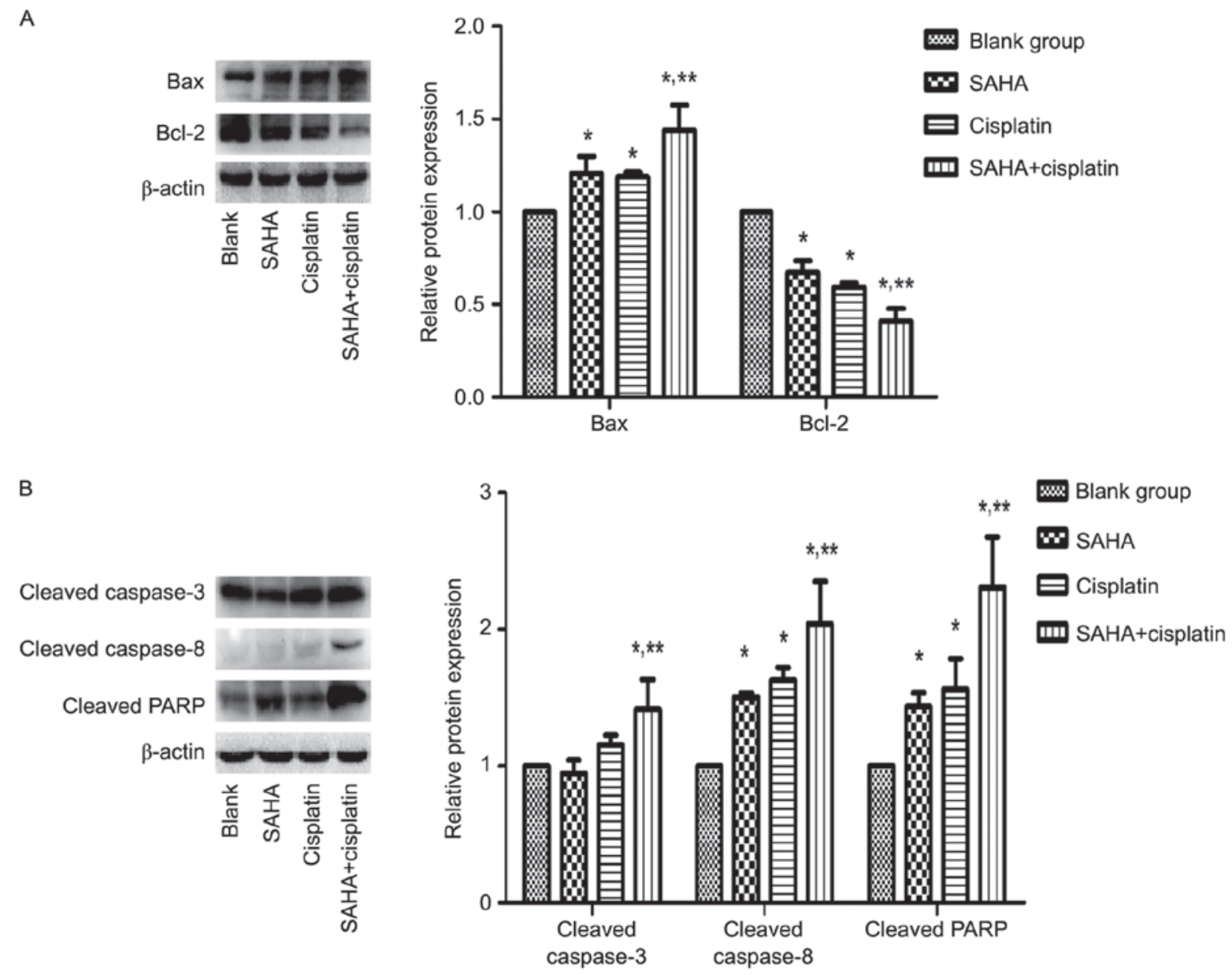

Figure 5. Western blot analysis of osteosarcoma cells treated with SAHA, cisplatin or SAHA+cisplatin. (A) Western blot analysis demonstrated that in 143B cells that were treated with SAHA/cisplatin, the protein expression level of Bax was increased whereas the protein expression level of Bcl-2 was decreased compared with the control and the monotherapy groups. (B) Following treatment with SAHA/cisplatin, the expression levels of cleaved-caspase-3, cleaved-caspase- 8 and cleaved-PARP were increased. ${ }^{*} \mathrm{P}<0.05$ vs. control; ${ }^{* *} \mathrm{P}<0.05$ vs. single treatment. Bcl, B cell lymphoma; SAHA, suberoylanilide hydroxamic acid.

tends to occur early and progress rapidly (25). The current management strategy for the majority of cases of osteosarcoma is surgery with chemotherapy (4). With the development of neoadjuvant intravenous combinational chemotherapy (doxorubicin and cisplatin with or without methotrexate) in the 1970s $(3,4)$, the 5-year survival rates steadily increased to as high as $81.6 \%$ (26). However, survival rates for patients with pulmonary metastasis or recurrence will be decreased compared with primary cases, highlighting the need for high-efficiency novel chemotherapeutics or chemotherapy sensitization agents (26).

Combination chemotherapy is the first choice for the treatment of numerous types of cancer, including acute leukemia and pancreatic ductal adenocarcinoma (27). Combining drugs that target different oncogenic cell signaling pathways often decreases the side-effects and complications in patients and increase the efficacy of treatment and decrease morbidity compared with conventional chemotherapy (28). Cisplatin is an effective cancer chemotherapy drug widely used for multiple types of tumor, including testicular, ovarian, lung, and head and neck cancer (29). It is also the first-line chemotherapy drug for therapy of osteosarcoma (30). Although cisplatin has a strong therapeutic effect, drug resistance and serious side effects limit its clinical application (31). SAHA, a pan-class I and class II HDAC inhibitor (32), has demonstrated anti-proliferation activity in numerous hematologic and solid tumor malignancy preclinical studies (32); however, numerous trials have verified the limitations of SAHA use for treatment of solid tumors $(33,34)$. The combination of SAHA with cisplatin has previously been revealed to be effective against malignancies (35). However, there are no reports of this combination being investigated in osteosarcoma either in vitro or in vivo. A previous study demonstrated that the combination of cisplatin with SAHA exerted an additive interaction in the viability of MCF7 cells, whereas in T47D cells there was a tendency to synergy (36). Therefore, the present study hypothesized that SAHA combined with cisplatin may enhance the antitumor effects of cisplatin in osteosarcoma cell lines.

To assess our hypothesis, the present study selected 143B cells from human osteosarcoma to perform the following analyses. The anti-proliferation activity of single drugs (SAHA or cisplatin) in 143B human osteosarcoma cells was evaluated by MTT assay. The results revealed that SAHA or cisplatin exerted a toxic effect on osteosarcoma 143B cells in a concentration- and time-dependent manner. The combination of SAHA and cisplatin induced an increased inhibitory 
effect on 143B cells with a combination index $<1$ (calculated using the CalcuSyn software 1.0), which implied that SAHA may promote the anti-proliferation effect of cisplatin on 143B cells. The combined therapy also significantly inhibited colony-formation ability and the necrosis of 143B cells was increased in the combination group compared with the control and the two individual treatment groups. In addition, the cell migration rate in the co-treatment group was significantly decreased compared with that in the two single drug groups and the early apoptotic rate in 143B cells treated with the combined regimens was significantly increased compared with that in the two single drug groups. The present study also demonstrated that the combination of SAHA and cisplatin inhibited osteosarcoma cell proliferation by modulating the cell cycle.

Caspases are a family of protease enzymes that serve critical functions in programmed cell death and inflammation. Activation of caspases ensures that the cellular components are degraded in a controlled manner, performing cell death with minimal effect to surrounding tissues (37). Caspase- 8 is an initial caspase essential for the transduction of the apoptotic cascade where downstream effector caspase- 3 becomes activated and cleaves target proteins, eventually inducing apoptosis (38). Caspase-3 is a caspase protein that interacts with caspase- 8 and its activation is often used to evaluate apoptosis in studies of antitumor drugs (39-41). PARP is a family of proteins associated with numerous cellular processes involving DNA repair and programmed cell death. The results of the present study demonstrated that single treatment (SAHA or cisplatin) and combination treatment (SAHA + cisplatin) increased the expression levels of cleaved-caspase-3, -8 and cleaved-PARP, which may induce apoptosis via the caspase signaling pathway. The expression levels of caspase-3, -8 and cleaved-PARP protein in combination treatment cells were significantly increased compared with those in single drug groups.

The results of the present study may provide a basis to further investigate this treatment combination in animal models. The present study has certain limitations. We only used human osteosarcoma 143B cells; however, there are numerous human osteosarcoma cell lines, including MG63, $\mathrm{U} 2 \mathrm{OS}$ and Saos2. Further research is required to investigate whether SAHA combined with cisplatin is effective in other human osteosarcoma cell lines and elucidate the underlying mechanisms.

To conclude, the present study assessed the effects of SAHA or cisplatin alone and in combination on cell proliferation, migration, colony-formation ability, apoptosis and cell cycle distribution of 143B cells. The results demonstrated that the combinatorial treatment of SAHA and cisplatin may inhibit the proliferation and migration and promote the apoptosis of osteosarcoma 143B cells synergistically in vitro. Consequently, the present study suggested that the SAHA/cisplatin combination should be further studied for its use in the treatment of osteosarcoma.

\section{Acknowledgements}

The present study was supported by the National Natural Science Foundation of China (grant nos. 81102035 and
81500129) and the Program of Educational Commission Foundation of Chongqing, China (grant no. KJ1500215).

\section{Competing interests}

The authors declare that they have no competing interests.

\section{References}

1. Siclari VA and Qin L: Targeting the osteosarcoma cancer stem cell. J Orthop Surg Res 5: 78, 2010.

2. Hossain MS, Begum M, Mian MM, Ferdous S, Kabir S Sarker HK, Karim S, Choudhury S, Khan A, Khan ZJ and Karim-Kos HE: Epidemiology of childhood and adolescent cancer in Bangladesh, 2001-2014. BMC Cancer 16: 104, 2016.

3. Bacci G, Longhi A, Versari M, Mercuri M, Briccoli A and Picci P: Prognostic factors for osteosarcoma of the extremity treated with neoadjuvant chemotherapy: 15-year experience in 789 patients treated at a single institution. Cancer 106: 1154-1161, 2006.

4. Ferrari S, Smeland S, Mercuri M, Bertoni F, Longhi A, Ruggieri P, Alvegard TA, Picci P, Capanna R, Bernini G, et al: Neoadjuvant chemotherapy with high-dose Ifosfamide, high-dose methotrexate, cisplatin, and doxorubicin for patients with localized osteosarcoma of the extremity: A joint study by the Italian and Scandinavian Sarcoma Groups. J Clin Oncol 23: 8845-8852, 2005.

5. Dasari S and Tchounwou PB: Cisplatin in cancer therapy: Molecular mechanisms of action. Eur J Pharmacol 740: 364-378, 2014.

6. Siddik ZH: Cisplatin: Mode of cytotoxic action and molecular basis of resistance. Oncogene 22: 7265-7279, 2003.

7. Fennell DA, Summers Y, Cadranel J, Benepal T, Christoph DC, Lal R, Das M, Maxwell F, Visseren-Grul C and Ferry D: Cisplatin in the modern era: The backbone of first-line chemotherapy for non-small cell lung cancer. Cancer Treat Rev 44: 42-50, 2016.

8. Douillard JY, Eckardt J and Scagliotti GV: Challenging the platinum combinations in the chemotherapy of NSCLC. Lung Cancer 38 (Suppl 4): S21-S28, 2002.

9. Graham JS, Kaye SB and Brown R: The promises and pitfalls of epigenetic therapies in solid tumours. Eur J Cancer 45: 1129-1136, 2009.

10. Atala A: Re: SAHA triggered MET activation contributes to SAHA tolerance in solid cancer cells. J Urol 194: 848-849, 2015.

11. Lakshmaiah KC, Jacob LA, Aparna S, Lokanatha D and Saldanha SC: Epigenetic therapy of cancer with histone deacetylase inhibitors. J Cancer Res Ther 10: 469-478, 2014.

12. Mai A, Massa S, Rotili D, Cerbara I, Valente S, Pezzi R, Simeoni S and Ragno R: Histone deacetylation in epigenetics: An attractive target for anticancer therapy. Med Res Rev 25: 261-309, 2005.

13. Blattmann C, Oertel S, Ehemann V, Thiemann M, Huber PE, Bischof M, Witt O, Deubzer HE, Kulozik AE, Debus J and Weber KJ: Enhancement of radiation response in osteosarcoma and rhabdomyosarcoma cell lines by histone deacetylase inhibition. Int J Radiat Oncol Biol Phys 78: 237-245, 2010.

14. Castro-Galache MD, Ferragut JA, Barbera VM, Martín-Orozco E, Gonzalez-Ros JM, Garcia-Morales P and Saceda M: Susceptibility of multidrug resistance tumor cells to apoptosis induction by histone deacetylase inhibitors. Int J Cancer 104: 579-586, 2003.

15. Luong QT, O'Kelly J, Braunstein GD, Hershman JM and Koeffler HP: Antitumor activity of suberoylanilide hydroxamic acid against thyroid cancer cell lines in vitro and in vivo. Clin Cancer Res 12: 5570-5577, 2006.

16. Hiriyan J, Shivarudraiah P, Gavara G, Annamalai P, Natesan S, Sambasivam G and Sukumaran SK: Discovery of PAT-1102, a novel, potent and orally active histone deacetylase inhibitor with antitumor activity in cancer mouse models. Anticancer Res 35: 229-237, 2015.

17. Modesitt SC, Sill M, Hoffman JS and Bender DP; Gynecologic Oncology Group: A phase II study of vorinostat in the treatment of persistent or recurrent epithelial ovarian or primary peritoneal carcinoma: A gynecologic oncology group study. Gynecol Oncol 109: 182-186, 2008.

18. Duvic M and Vu J: Vorinostat: A new oral histone deacetylase inhibitor approved for cutaneous T-cell lymphoma. Expert Opin Investig Drugs 16: 1111-1120, 2007. 
19. Takai $\mathrm{N}$ and Narahara H: Preclinical studies of chemotherapy using histone deacetylase inhibitors in endometrial cancer. Obstet Gynecol Int 2010: 923824, 2010.

20. Kelly WK, Richon VM, O'Connor O, Curley T, MacGregor-Curtelli B, Tong W, Klang M, Schwartz L, Richardson S, Rosa E, et al: Phase I clinical trial of histone deacetylase inhibitor: Suberoylanilide hydroxamic acid administered intravenously. Clin Cancer Res 9: 3578-3588, 2003.

21. Diyabalanage HV, Granda ML and Hooker JM: Combination therapy: Histone deacetylase inhibitors and platinum-based chemotherapeutics for cancer. Cancer Lett 329: 1-8, 2013.

22. van Roosmalen W, Le Dévédec SE, Golani O, Smid M,Pulyakhina I, Timmermans AM, Look MP, Zi D, Pont C, de Graauw M, et al: Tumor cell migration screen identifies SRPK1 as breast cancer metastasis determinant. J Clin Invest 125: 1648-1664, 2015

23. Bailon-Moscoso N, Cevallos-Solorzano G, Romero-Benavides JC and Orellana MI: Natural compounds as modulators of cell cycle arrest: Application for anticancer chemotherapies. Curr Genomics 18: 106-131, 2017.

24. Alfranca A, Martinez-Cruzado L, Tornin J, Abarrategi A, Amaral T, de Alava E, Menendez P, Garcia-Castro J and Rodriguez R: Bone microenvironment signals in osteosarcoma development. Cell Mol Life Sci 72: 3097-3113, 2015.

25. Zhang Y, Zhang L, Zhang G, Li S, Duan J, Cheng J, Ding G, Zhou C, Zhang J, Luo P, et al: Osteosarcoma metastasis: Prospective role of ezrin. Tumour Biol 35: 5055-5059, 2014.

26. Allison DC, Carney SC, Ahlmann ER, Hendifar A, Chawla S, Fedenko A, Angeles C and Menendez LR: A meta-analysis of osteosarcoma outcomes in the modern medical era Sarcoma 2012: 704872, 2012.

27. Bayat Mokhtari R, Homayouni TS, Baluch N, Morgatskaya E, Kumar S, Das B and Yeger H: Combination therapy in combating cancer. Oncotarget 8: 38022-38043, 2017.

28. Sato T, Suzuki M, Sato Y, Echigo S and Rikiishi H: Sequence-dependent interaction between cisplatin and histone deacetylase inhibitors in human oral squamous cell carcinoma cells. Int J Oncol 28: 1233-1241, 2006.

29. Galanski M: Recent developments in the field of anticancer platinum complexes. Recent Pat Anticancer Drug Discov 1: 285-295, 2006.

30. Longhi A, Errani C, De Paolis M, Mercuri M and Bacci G: Primary bone osteosarcoma in the pediatric age: State of the art. Cancer Treat Rev 32: 423-436, 2006.
31. Reedijk J: New clues for platinum antitumor chemistry: Kinetically controlled metal binding to DNA. Proc Natl Acad Sci USA 100: 3611-3616, 2003.

32. Marks PA: Discovery and development of SAHA as an anticancer agent. Oncogene 26: 1351-1356, 2007

33. Blumenschein GR Jr, Kies MS, Papadimitrakopoulou VA, Lu C, Kumar AJ, Ricker JL, Chiao JH, Chen C and Frankel SR: Phase II trial of the histone deacetylase inhibitor vorinostat (Zolinza, suberoylanilide hydroxamic acid, SAHA) in patients with recurrent and/or metastatic head and neck cancer. Invest New Drugs 26: 81-87, 2008.

34. Vansteenkiste J, Van Cutsem E, Dumez H, Chen C, Ricker JL, Randolph SS and Schöffski P: Early phase II trial of oral vorinostat in relapsed or refractory breast, colorectal, or non-small cell lung cancer. Invest New Drugs 26: 483-488, 2008.

35. Jin KL, Park JY, Noh EJ, Hoe KL, Lee JH, Kim JH and Nam JH: The effect of combined treatment with cisplatin and histone deacetylase inhibitors on HeLa cells. J Gynecol Oncol 21: 262-268, 2010.

36. Wawruszak A, Luszczki JJ, Grabarska A, Gumbarewicz E, Dmoszynska-Graniczka M, Polberg K and Stepulak A: Assessment of interactions between cisplatin and two histone deacetylase inhibitors in MCF7, T47D and MDA-MB-231 human breast cancer cell lines - an isobolographic analysis. PLoS One 10: e0143013, 2015.

37. Rathore S, Datta G, Kaur I, Malhotra P and Mohmmed A: Disruption of cellular homeostasis induces organelle stress and triggers apoptosis like cell-death pathways in malaria parasite. Cell Death Dis 6: e1803, 2015.

38. Pu F, Chen F, Lin S, Chen S, Zhang Z, Wang B and Shao Z: The synergistic anticancer effect of cisplatin combined with Oldenlandia diffusa in osteosarcoma MG-63 cell line in vitro. Onco Targets Ther 9: 255-263, 2016.

39. Porter AG and Jänicke RU: Emerging roles of caspase-3 in apoptosis. Cell Death Differ 6: 99-104, 1999.

40. Kaufmann SH, Lee SH, Meng XW, Loegering DA, Kottke TJ, Henzing AJ, Ruchaud S, Samejima K and Earnshaw WC: Apoptosis-associated caspase activation assays. Methods 44: 262-272, 2008

41. Häcker G and Paschen SA: Therapeutic targets in the mitochondrial apoptotic pathway. Expert Opin Ther Targets 11: 515-526, 2007. 